\title{
DECONSTRUYENDO LA CATEGORÍA DE MUJERES VÍCTIMAS DEL DESPLAZAMIENTO EN COLOMBIA*
}

\author{
DECONSTRUCTING THE CATEGORY OF WOMEN VICTIMS OF \\ DISPLACEMENT IN COLOMBIA
}

\author{
Catalina Revollo-Pardo**
}

\section{Resumen}

Objetivo. Deconstruir la categoría de mujeres víctimas del desplazamiento en Colombia. Metodología. Se realizó un análisis del contenido de los testimonios de las mujeres víctimas del desplazamiento que participaron de la investigación traduciendo los testimonios de las mujeres víctimas del desplazamiento en Colombia. Resultados. Los resultados localizaron en los testimonios elementos y hechos del cotidiano de las mujeres víctimas, referentes a los procesos de militancia política en las organizaciones de base y en el movimiento de víctimas a nivel nacional, analizándolos desde la perspectiva de género de los estudios feministas poscoloniales y decoloniales. Conclusión. La categoría de mujeres víctimas se articula desde la lógica de los procesos de militancia política, la cual está atravesada por la lógica de la sociedad patriarcal que las victimiza de varias maneras, y en contraposición generan estrategias de reexistencia, resignificando su condición de mujeres víctimas.

Palabras clave: mujeres víctimas, género, posconflicto, psicosociología de comunidades.

\begin{abstract}
Objective. To deconstruct the category of women victim of displacement in Colombia. Methodology. An analysis of the content of the testimonies of women victim of displacement who participated in the research Translating the testimonies of women victim of displacement in Colombia was carried out. Results. The results found in the testimonies elements and facts of the daily life of the women victim of displacement, that make reference to the processes of political militancy in grassroots organizations and in the movement of victims nationwide, analyzing them from the gender perspective of the postcolonial and decolonial feminist studies. Conclusion. The category of victim women is articulated from the logic of the processes of political militancy, which is crossed by the logics of the patriarchal society that victimizes them in various ways, and in contrast generate re-existence strategies, resignifying their status as victim women.
\end{abstract}

Key words: victim women, gender, post-conflict, psychosociology of communities.

\footnotetext{
* Este artículo se deriva de la investigación de la autora: Traduciendo los testimonios de las mujeres víctimas del desplazamiento en Colombia (Revollo, 2015), tesis (Doctorado en Psicosociología de Comunidades y Ecología Social) - Instituto de Psicología de la Universidad Federal de Rio de Janeiro, Rio de Janeiro, 2015. El objetivo de esta tesis fue investigar los testimonios de mujeres colombianas víctimas de desplazamiento, desde la perspectiva de la traducción cultural en el marco de la crítica decolonial y poscolonial. El trabajo de campo se realizó en Bogotá con miembros de tres organizaciones gestionadas por víctimas del desplazamiento forzado en Colombia, y dos miembros una Red de Maestros y Maestras Investigadores Etnoeducadores. Los desplazamientos forzados de las mujeres víctimas que participaron de esta tesis fueron generados por grupos paramilitares en diversas regiones de Colombia, entre los años 2004 y 2014. Esta investigación concluyó que las mujeres víctimas del desplazamiento forzado en Colombia asumen de manera diferenciada su condición de víctimas, generando estrategias organizativas contrahegemónicas para atender su condición de víctimas y emprender la construcción de un nuevo país donde las víctimas son reconocidas como actores políticos.

${ }^{* * *}$ Universidad Federal de Rio de Janeiro. Rio de Janeiro, Brasil. E-mail: carevollo@gmail.com-

(D) orcid.org/0000-0003-1469-4456 Google Scholar
} 


\section{Introducción}

Con la intención de aportar elementos para los estudios de género y posconflicto en Colombia, este artículo analiza el contenido de los testimonios de 11 mujeres víctimas del desplazamiento participantes de la investigación doctoral: Traduciendo los testimonios de las mujeres víctimas del desplazamiento en Colombia (Revollo, 2015), con el objetivo de deconstruir la categoría de mujeres víctimas.

La población víctima del conflicto social, político, económico y armado colombiano, no se ha conformado con asumir pasivamente la categoría de víctima emitida por el aparato legislativo del Estado colombiano. Las víctimas en Colombia han sido activas en la conformación de movimientos sociales y procesos políticos para reivindicar sus derechos, y por medio de nuevas alternativas alteran las estructuras desiguales e injustas generadas por el modelo "democrático"1 del país.

En Colombia hay una lucha por la definición de la categoría 'víctimas'. Es esencial reconocer la diferencia cuando las víctimas hablan de víctimas, a cuando el gobierno Santos habla de las víctimas o cuando el gobierno Uribe habló de víctimas. Es posible que el término víctima adquiera un estatuto en la Ley 975 de 2005 de Justicia y Paz y en la Ley de Víctimas 1448 de 2011, pero es menester recordar que esta categoría ya ha sido enunciada anteriormente por los diferentes movimientos de víctimas en el país. El análisis de la categoría de víctima propuesto por la antropóloga Jimeno (2010) se estructura desde la construcción cultural del movimiento indígena del Alto Naya en el Cauca. Según Jimeno, esta comunidad viene elaborando hace algún tiempo un lenguaje emocional, conformando lo que ella denomina comunidades emocionales fundadas en la ética del reconocimiento, así la enunciación del término víctima de las comunidades permite ventilar de manera inédita en Colombia los hechos violentos desde la óptica de las y los que los sufrieron.

Las múltiples situaciones y lecturas que tiene el conflicto, dependiendo del lugar que se haya vivenciado, hacen que el universo de las víctimas sea complejo. Los grupos paramilitares, la insurgencia, el ejército y las transnacionales cargan con sus propias víctimas y, en torno de esta condición, las víctimas se han organizado diferenciando quiénes son las/los víctimas (mujeres, niños, hombres, comunidades afrocolombianas o comunidades indígenas), quiénes son los actores que las han victimizado y cuáles son los hechos victimizantes ${ }^{2}$ que les generaron esta condición. Así, cada proceso parte de realidades, experiencias y posturas políticas diferentes.

\footnotetext{
${ }^{1}$ Con una política neoliberal y una estrategia militar vinculada al dominio de Estados Unidos en la región, por ello el motivo de las comillas para el adjetivo democrático.

${ }^{2}$ Según la legislación actual de víctimas Ley 1448 de 2011 - Decreto Nacional 4800 de 2011, son 13 las modalidades de violencia aplicadas sobre la población civil: (a) desplazamiento forzado, (b) despojo de tierras, (c) secuestro, (d) extorsión, (e) reclutamiento ilícito de niñas, niños y adolescentes, (f) tortura, ( $\mathrm{g}$ ) homicidio en persona protegida, asesinatos selectivos y masacres, (h) amenazas, (i) delitos contra la libertad y la integridad sexual, (j) desaparición forzada, (k) minas antipersona, munición sin explotar y artefactos explosivos convencionales, (l) ataques y pérdidas de bienes civiles, $(\mathrm{m})$ atentados contra bienes públicos (Ley 1448 de 2011).
} 
(...) nosotros hemos vuelto a decir que el sector de las víctimas, que hoy estamos en ese universo, que todos, incluso los mismos victimarios y las mismas fuerzas militares, entonces los victimarios entran a ser parte de ese universo de víctimas (...) hoy todavía seguimos proclamando un nuevo orden social y político para el país a través de la constituyente nacional y de la participación de los procesos social y popular, pero seguimos haciendo en el marco del contexto y de la legislación actual y entonces eso nos divide, nos divide en el discurso y en la unidad de acción porque para nosotros el planteamiento tiene que ser por fuera de la Ley de Víctimas, tiene que ir más allá, tiene que reconocer las comunidades en resistencia, las comunidades en riesgo de desplazamiento, y porque sí, nosotros somos campesinos desplazados y en resistencia en las ciudades. (Luz ${ }^{3}$, comunicación personal, 26 de febrero de 2014)

El testimonio de Luz nos explica la complejidad del escenario político del movimiento víctimas generado por la Ley 1448 de 2011, donde todas las víctimas han sido agrupadas sin prever una diferenciación de las características de su victimización. Ella destaca que esta omisión ha dejado cara a cara a las víctimas y a sus victimarios. Este hecho generó que las víctimas organizaran sus procesos políticos diferenciando los actores que generaron su victimización, resaltando cuando una víctima ha sido victimizada por los paramilitares, o cuando ha sido victimizada por los grupos insurgentes, o cuando ha sido victimizada por el Estado, o cuando ha sido victimizada por las empresas transnacionales en territorio colombiano. En el presente artículo son analizados los testimonios de mujeres que han sido victimizadas por los grupos paramilitares y el hecho que las victimizó ha sido el desplazamiento forzado, relacionado a la violencia de género.

El desplazamiento ${ }^{4}$ en Colombia es considerado un fenómeno de migración interna forzada y extremadamente complejo, marcado por múltiples causas y varias modalidades. Va más allá de una consecuencia lineal de escape (causa-efecto) de la población civil colombiana, para resguardar su integridad física y emocional de hechos violentos ocurridos entre los actores armados del conflicto, pues el cotidiano de la población civil colombiana (rural y urbana) está integrado a la complejidad del conflicto social-político-económico-armado, generado por la propia lógica del régimen “democrático” neoliberal.

En su trabajo, Mondragón (2002) - profesor economista, exiliado por la violencia- afirma: "No sólo hay desplazados porque hay guerra, sino especialmente hay guerra para que haya

\footnotetext{
${ }^{3}$ Testimonio cedido por el seudónimo 'Luz' (Revollo, 2015).

${ }^{4}$ Para el caso de las víctimas del desplazamiento es importante destacar que la denominación 'desplazado' viene en la Ley 397 de 1997, que durante años connotó al desplazado como población vulnerable, con dificultad de entender a la persona desplazada forzada como víctima. Para la época no se denominaba "persona víctima del desplazamiento", sino "persona en situación de desplazamiento” (Centro Nacional de Memoria Histórica-CNMH, 2013).
} 
Deconstruyendo la categoría de mujeres víctimas del desplazamiento en Colombia

desplazados" (p. 5). Esta acertada crítica del profesor se relaciona con los aportes de Fajardo (2015) en su informe para la Comisión Histórica y de las Víctimas de la mesa de diálogos de La Habana, en la que enmarca la complejidad del fenómeno del desplazamiento colombiano en la lógica de apropiación y concentración de las tierras por parte de los actores del Estado, las élites económicas y las transnacionales. Lo que ha llevado a la "pertinente" y violenta expulsión del campesinado (de sus tierras) y de las comunidades ancestrales (de sus territorios), alejándolos de los procesos productivos agrícolas, para abrirle espacio al agronegocio y la locomotora extractiva.

Son aproximadamente 8’425.398 las víctimas desde 1985 hasta 2017, según las estadísticas oficiales del Registro Único de Víctimas. Se estima que cerca de 7’400.000 son víctimas del desplazamiento forzado (a nivel rural y urbano - interurbano y/o intraurbano). Las mujeres son aproximadamente más de la mitad de la población víctima del desplazamiento en Colombia, y sus desplazamientos están marcados por circunstancias relacionadas a la condición de género.

Para empezar presentaré el referencial teórico del artículo por medio de un diálogo entre las propuestas de la colonialidad del poder y la colonialidad de género, y un análisis sobre la representación relacionada a la categoría de mujeres víctimas del desplazamiento. Después presentaré la metodología, la cual está basada en el análisis del contenido de los testimonios de las mujeres víctimas del desplazamiento. Luego presentaré los resultados, donde por medio de los testimonios se analizarán los elementos y hechos narrados que revelan la condición del lugar de la victimización de las mujeres víctimas del desplazamiento en sus contextos de militancia.

\section{Referencial teórico - Aportes del feminismo decolonial para la deconstrucción de la categoría mujeres víctimas}

Para deconstruir la categoría mujeres víctimas es necesario cuestionar el proceso de representación, la comprensión de que hay una "otra"/un "otro" creada por un sistema de conocimiento masculino y colonial. Es indispensable para entender cómo la crítica decolonial y el feminismo decolonial analizan el conocimiento que se ha generado desde epistemologías coloniales de la historia "universal" o la filosofía occidental. Donde la "otra"/el "otro" es una creación europea que parte de la colonización, en la relación de alteridad entre las/ los indígenas, las/los negra/os y las/los europeas/os y que se mantiene en la actualidad de diversas maneras ${ }^{5}$.

Las/os "otras"/“otros”, no son solo las/los no occidentales. Dentro del mismo Occidente hay más "otras”/“otros” delimitadas/os por las diferencias económicas, políticas, de género

${ }^{5}$ Las tres descubiertas imperiales, que plantea De Sousa Santos (2008), son: El Oriente, la Naturaleza y el Salvaje. 
y étnicas. El modelo masculino blanco cristiano capitalista es el modelo hegemónico "universalizante", que inferioriza y somete todo lo que sale de su norma, manteniendo a las/ los otras/os en las periferias del sistema. Los procesos de militancia política de las mujeres víctimas del desplazamiento en las grandes ciudades cuestionan, a través de su lucha popular y femenina, la organización de este sistema mundo colonial masculino.

La representación, según Bahri (2004), sucede por medio de la reproducción, la semejanza, la formación de una idea en el espíritu, o la misma presencia por darle sentido a un "portavoz" político, es decir, una persona o grupo que habla en nombre de otras personas o grupos. Estas / os "otras/os" para el discurso dominante no tienen palabra, o voz, para elaborar su propio retrato. Ellas/os están reducidas/os a ser aquellas/os por quienes hablamos, porque hablan aquellas/os que poseen el poder y la manera para hablar. Aquellas/os que poseen el poder de representar y de describir a las/os otras/os, controlan la manera con que estas/os últimas/ os serán vistos.

Spivak (2003) reflexiona sobre el peligro de la apropiación de otra/o por la asimilación, ya que esta perspectiva toma como verdad lo que es dicho de la/del otra/o, haciendo que tal discurso quede en la conciencia de la/del más débil. La autora está interesada en proponer una relectura sobre lo que se mantiene como verdad, discutiendo la capacidad de la subalterna de representarse, destacando que la posición del sujeto es construida en el interior del discurso, más de que en lo preexistente a este.

La representación es siempre ficcional o parcial y revela la complejidad de la relación entre "Primer Mundo" y “Tercer Mundo”, afirmando la construcción monolítica de mujeres no occidentales que son el objeto y la usurpación del espacio de representación por las mujeres originarias del Tercer Mundo que viven en el Occidente (Bahri, 2004).

Las categorías utilizadas por el sistema hegemónico para diferenciar unas mujeres de otras, fueron perjudiciales para la expresión de sus testimonios. Mismo que ellas puedan verbalizar sus testimonios, estos son interpretados desde una perspectiva patriarcal e imperial. Para que la lucha de las mujeres sea escuchada, es necesario articularla al reconocimiento de sus testimonios, siendo así los sujetos de las márgenes narran sus propias historias para construir una memoria que ha sido ignorada por la razón occidental hegemónica, por esto, estas historias de vida se narran de abajo para arriba. La cuestión no es solo que las subalternas no pueden hablar, es también tomar conciencia de que las subalternas no pueden hablar.

Para comprender lo anterior es importante evocar el concepto de la colonialidad del poder de Quijano (2005), con el cual explica el actual patrón de poder del sistema mundo derivado de la herida colonial. Quijano destaca que uno de los elementos fundamentales del actual patrón 
de poder es la clasificación social en torno de la idea de "raza”, vigente hace 500 años en el proceso de colonización a América por parte de Europa que implicó la implementación del capitalismo. Según el autor, la clasificación social en torno de la idea de raza es la más profunda y perdurable expresión de la dominación colonial, presente en todas y cada una de las áreas de existencia social, y constituye la más profunda y eficaz forma de dominación social del actual padrón mundial del poder capitalista.

Partiendo del concepto de la colonialidad del poder de Quijano se generó la crítica de Lugones (2008), quien propone la idea de la colonialidad de género, la cual está subordinada a la jerarquía de la clasificación racial. Según la autora, cuando se trae la categoría de género para el centro del proyecto colonial, se puede analizar la genealogía de su formación y utilización como un mecanismo fundamental por el cual el capitalismo colonial global estructuró las asimetrías de poder en el mundo contemporáneo, evidenciando cómo el patriarcado, el capitalismo y la clasificación racial se encuentran articuladas.

Lugones (2008) nos hace pensar la intersección de las categorías género y raza (las cuales están conceptualizadas separadamente), motivada por las dificultades de hacer visible quién está siendo dominado y victimizado. Lo que significa que, a pesar de que todo el mundo en la modernidad capitalista eurocéntrica está atravesado por la categoría de raza y la categoría de género, no todo el mundo es dominado o victimizado por la raza o por el género.

Estas categorías han sido planteadas homogéneas en la colonialidad del poder de Quijano (2005), de esta manera el dominante en el grupo escoge la norma, por lo tanto, las mujeres escogen mujeres burguesas blancas, los hombres escogen los hombres blancos burgueses, los negros escogen hombres heterosexuales negros, etc. Dada esa construcción de las categorías, parece evidente que la lógica de la separación de categorías distorsiona lo que existe en las intersecciones, generando violencia hacia la mujer negra. De esta manera la intersección nos muestra lo que falta, dejándonos la tarea de reconceptualizar la lógica de la intersección de las categorías, para evitar la separación, pues solo cuando planteamos el género y la raza entrelazados o fusionados, es que vemos realmente a las mujeres (Lugones, 2008).

La colonialidad de género rearticula críticamente la colonialidad del poder, abriendo un importante espacio para el feminismo decolonial, que lucha por un proyecto de descolonización y feminización del saber eurocéntrico-colonial-patriarcal, a través del poder interpretativo, llegando a lo que Walsh (2009) plantea como la interculturalidad sobre la geopolítica del

\footnotetext{
${ }^{6}$ La idea de "raza" en América Latina, según Quijano (2005), fue una manera de legitimar las relaciones de dominación impuestas por la Conquista. Se establece al hombre blanco europeo como superior, que domina y explota a negros e indígenas, para ese entonces no considerados como seres humanos, de acuerdo con las discusiones del Tratado de Valladolid en 1605. La expansión del colonialismo europeo por el resto del mundo conducía al desarrollo de la perspectiva eurocéntrica del conocimiento relacionada a la idea de raza, que comprobó ser el instrumento más eficaz, duradero y universal de dominación social hasta los días de hoy.
} 
conocimiento y la necesidad de construir nuevas cosmologías y epistemologías a partir de otros lugares de enunciación, incluyendo la traducción translocal de esos otros espacios de teorización, interpretación e intervención.

La estrategia de las feministas del Occidente es construir la categoría mujer del Tercer Mundo, como un concepto esencializado para desarrollar una idea fija de un estereotipo invariable y así justificar los programas de desarrollo y de compensación para reparar efectivamente los daños cometidos históricamente a individuos o grupos desde una perspectiva colonial. El feminismo hegemónico del Norte pretende mantener sus intereses normativos de legitimación social de clase, raza, sexualidad y género. Son muchas las mujeres feministas de la periferia que apoyan este proyecto hegemónico, lo que hace difícil la agencia de las mujeres subalternas a este régimen normativo. En esta línea Miñoso (2009) argumenta: "Es necesaria una comunidad feminista transfronteriza, anticapitalista y descolonizada, soportada por la idea de las 'diferencias comunes' que desarrollan una lucha contra los efectos de la globalización, promoviendo un horizonte de justicia y solidaridad” (p. 41).

Anzaldúa (2005) enfatiza en que los terrenos de la diferencia son más que nunca espacios de poder. La autora complica radicalmente el discurso feminista de la diferencia, inclusive de la diferencia colonial. Migrando por los entre-lugares de la diferencia constitutiva de la historia, que adquiere forma a partir de las intersecciones siempre locales (sus muchos mestizajes revelan simultáneamente mecanismos de sometimiento y ocasiones para el ejercicio de la libertad).

La acción traductora de Anzaldúa (2005) combina el mundo y las identidades, siendo una práctica para el cuestionamiento de nuestras seguridades epistemológicas, buscando la abertura para otras formas de conocimiento y de humanidades. Lo que se completa con la opinión de Curiel (2011) del hecho de que el conocimiento también se produce en la experiencia, que no existe esa separación de teoría y práctica, pues la práctica también produce conocimiento: una nueva epistemología, no solamente para el movimiento feminista, sino también para toda la teoría y práctica crítica.

\section{Metodología - Análisis de los testimonios de las mujeres víctimas del desplazamiento: el camino para deconstruir la categoría mujer víctima del desplazamiento}

El testimonio abre caminos para evocar los recuerdos de las memorias de los grupos y los sujetos que pertenecen a estos grupos. Específicamente los testimonios sobre hechos victimizantes, son evocados con la finalidad de recuperar las memorias de los hechos para desestabilizar los discursos hegemónicos, que pretenden manipular el pasado con finalidades perversas. Según 
Sarlo (2007): "Cuando acabaron las dictaduras de Sur América, recordar fue una actividad de restauración de los lazos sociales comunitarios perdidos en el exilio o destruidos por la violencia de Estado. Tomaron la palabra, las víctimas y sus representantes” (p. 45).

El choque de la violencia de Estado no fue una barrera para escuchar y construir la narración de la experiencia sufrida. Las dictaduras representaron una ruptura de época y, así mismo, no existió el silenciamiento, por el contrario, los discursos testimoniales fueron importantes para restaurar la esfera pública de los derechos (Sarlo, 2007).

Los testimonios de las víctimas del desplazamiento son el legado de una población que busca hacer justicia. Una justicia más humana, que defiende el derecho a la vida, buscando abrir caminos para un reconocimiento y una redistribución justa a esta población, que necesita abrir nuevos espacios en otros contextos sociales totalmente desconocidos, como lo es la vida en las grandes ciudades.

Hacer aparecer estos testimonios del cotidiano de la militancia de las mujeres víctimas, tiene la intención de describir las dinámicas de opresión patriarcal de las mujeres desplazadas que luchan por: un retorno con garantías ${ }^{7}$, una reparación, una vida digna en la ciudad (en cuanto retornan).Y todo lo anterior, en el contexto de una sociedad libre de la opresión patriarcal.

La deconstrucción será realizada por medio del análisis de contenido de los testimonios, para detalladamente analizar los elementos y hechos que marcan el cotidiano de los procesos de militancia política de las mujeres víctimas. Es necesario, como dice Das (2008), "presenciar el descenso hacia la vida cotidiana a través de la cual las víctimas y los sobrevivientes afirman la posibilidad de la vida" (p. 167). Lo cual, para el caso colombiano, es pertinente relacionarlo con la lectura de Jimeno (2008) sobre la propuesta de Das:

(...) si el lenguaje del dolor es compartido, es posible aprender sobre las prácticas de interpretación del sufrimiento humano y su papel constitutivo en los procesos sociales, como lo propone Byron Good (2003). Por esto considero relevantes las narrativas y los testimonios sobre experiencias de violencia, también su expresión ritual o de ficción, porque son tanto clave de sentido, como medios de creación de un campo intersubjetivo, en el cual se comparte, al menos de modo parcial, el sufrimiento y puede anclarse la reconstrucción de ciudadanía. (p. 267)

\footnotetext{
${ }^{7}$ Las garantías del retorno, que plantea la población víctima del desplazamiento, no solo están relacionadas a las garantías de seguridad, son garantías que implican la redistribución de la tierra y la presencia del Estado (no solo militar), presencia de los servicios a los que los ciudadanos tenemos derecho en todas las regiones.
} 
Como se ha explicado a lo largo del texto, los testimonios analizados hacen parte de las tesis de doctorado: Traduciendo los testimonios de mujeres víctimas del desplazamiento en Colombia, los cuales fueron generados durante el trabajo de campo en los años 2013 y 2014, en la ciudad de Bogotá. Las mujeres víctimas con las que se trabajó son miembros de organizaciones de base $\operatorname{mixtas}^{8}$ construidas y administradas por las propias víctimas del desplazamiento. Las mujeres, que dieron sus testimonios, están insertadas en amplios procesos de militancia política del sector de la izquierda colombiana, articuladas a pautas y agendas de algunos movimientos sociales y políticos de lucha popular.

\section{Resultados - Testimonios sobre los procesos de militancia política de las mujeres víctimas del desplazamiento en procesos de deconstrucción}

Como lo analizamos en la introducción de este artículo, la categoría 'víctimas' ha sido tomada del movimiento de víctimas por los discursos y aparatos estatales oficiales. A continuación, es menester analizar desde la voz de las mujeres víctimas, lo que ellas problematizan en torno de la categoría de mujeres víctimas. Inicialmente se presentan los testimonios en que las mujeres explican cómo desarrollan sus procesos de militancia con los movimientos populares de campesinos en sus regiones, y cómo en la ciudades se articulan a los procesos del movimiento de víctimas, resaltando las dificultades que las mujeres pasan por el desplazamiento y sus vivencias en los movimientos de base, destacando las estrategias que ellas mismas desarrollan con una perspectiva diferenciada para las mujeres.

Luz $^{9}$ comienza la transitar en los procesos de militancia política desde pequeña en su región, en este sentido se cuestiona el lugar que le correspondía a la mujer en el sector rural colombiano y su decisión de trabajar en estos procesos:

(...) lo hice también como una lucha personal, es que no había mayores
posibilidades para los jóvenes, sobre todo para las niñas, para las mujeres
y me tocó ser mujer pero me tocó enfrentar muchos roles familiares y
para mí no fue tan fácil... en el campo se dice que ¿para qué una mujer
estudia?, es para tener un marido, unos hijos, entonces mi papá era una
persona que no había tenido mayor educación, campesino. Hombre,
patriarcal y machista, de todas maneras, entonces, imagínate uno en
medio de eso, entonces nací para tener un marido, casarme y tener
hijos y seguir el rol de él, de la finca, estar sometida de cierto modo la
mujer y entonces yo me preguntaba “iserá eso lo que yo quiero?” o sea
siempre, como aprendí muy chiquita a ir asumiendo esos roles, rol de

${ }^{8}$ Con miembros mujeres y hombres.

${ }^{9}$ Seudónimo. 


\begin{abstract}
la mujer, de ser mujer pero ser activista de estar con otros jóvenes, de aprender también muchas cosas políticas, entonces eso me permitía de pronto mirar la vida con otra opción diferente a la que la miraban el resto o muchas de las niñas que crecieron conmigo. (Luz, comunicación personal, 26 de febrero de 2014)
\end{abstract}

Esta experiencia para Luz fue importante para cuestionar su papel como mujer en la sociedad heteronormativa y patriarcal en que nació y creció, y sin embargo emprendió un proyecto de vida como mujer, donde trabajar en procesos de militancia política ha sido un vehículo cuestionador del rol de la mujer tradicionalmente establecido. En otro testimonio se evidencia que, antes de ser desplazadas, estas mujeres se dedicaban exclusivamente a las tareas del hogar en medio del contexto del conflicto. Ya la articulación a procesos de militancia política se da después del desplazamiento. La articulación a estos procesos generó nuevas dinámicas familiares, al tejerse redes de apoyo entre organizaciones y familias:

(...) yo también en ese proceso fui una mujer muy creativa porque fue un poquito traumático porque estaban muy pequeñitos [los hijos], perdieron cosas muy valiosas, como la familia, yo los metí en programas donde los ayudaron a despertar tantas cosas, tantas creatividades, paseamos juntos, estuvimos con una organización donde trabajan con niños y mujeres, nos los ganábamos porque era una integración, era todo en familia, entonces eso nos fortaleció. (Lourdes, comunicación personal, 22 de febrero de 2014)

La recursividad de las mujeres para moverse en los nuevos contextos urbanos es algo que ha caracterizado la manera como ellas asumen su lugar de víctimas. Ellas aprovechan múltiples espacios que las organizaciones abren y se articulan para crear otros más propios, como se observa en las diferentes iniciativas de procesos de base con la población de víctimas. En este caso el testimonio de Edelmira ${ }^{10}$ resalta la labor con las guarderías para los/las niños/as, como primera actividad organizativa que ella realizó con sus compañeras del barrio, desplazadas, para cubrir la necesidad de cuidado a los niños/as mientras las madres están trabajando. "Llegó un dinero y se hicieron los refugios infantiles" (Edelmira, comunicación personal, 18 de febrero de 2014).

Luz, al llegar a Bogotá por causa de su desplazamiento, se vincula a procesos de base de militancia política relacionados a la lucha de la población desplazada. Así que, al ingresar al movimiento, comienza a cuestionar el lugar de las mujeres víctimas en este contexto.

\footnotetext{
${ }^{10}$ Seudónimo.
} 
(...) en un proceso estuve vinculada más o menos cinco años y aprendí mucho, aprendí que el desplazamiento forzado afecta sobre todo a las mujeres, trabajé con muchas mujeres desde que arranqué el proceso, con muchas limitaciones porque las organizaciones también dirigidas por hombres, hombres campesinos, un poco el papel de la mujer queda relegado, dependemos de la opinión de ellos. (Luz, comunicación personal, 26 de febrero de 2014)

El cuestionamiento del lugar de las mujeres víctimas del desplazamiento en el contexto de la militancia política, en las organizaciones donde desarrollan este trabajo, ha generado la creación de espacios propios para la reflexión de las mujeres y el surgimiento de procesos diferenciados como lo observamos en el siguiente testimonio:
(...) en una organización de ayuda humanitaria, de ayuda solidaria empecé a militar allí, pero en vista de que los dirigentes todos eran muy machistas decidimos armar nuestro grupo aparte. Bueno allí nace la organización... en el 1998, 1999. En el 99 sacamos las personalidades jurídicas con el acompañamiento de una abogada, allí entonces ir a tocar puertas, visibilizar la situación de las desplazadas, a hablar sobre las mujeres que teníamos derecho, del derecho y género. (Edelmira, comunicación personal, 18 de febrero de 2014)

Los testimonios de las mujeres revelan que sus proyectos de vida han sido truncados por la violencia. Han sido obligadas a cambiar sus roles, oficios y actividades. Los relatos recrean cómo era la vida antes del desplazamiento, revelando que sus vidas estaban enmarcadas en relaciones patriarcales que les imponían altos grados de control, dominación y violencia por parte de los hombres miembros de sus familias. Después del desplazamiento sus relatos revelan que aun inmersas en el rol de cuidadoras, con sus múltiples y pesadas tareas del hogar, se les suman las responsabilidades económicas para sostener sus hogares, además de sobrellevar los impactos del desplazamiento. A todo lo anterior, se le deben incrementar las extensas jornadas para realizar los trámites burocráticos y procesos jurídicos, para conseguir el reconocimiento de su situación de víctimas y la de su familia (D’Ávila y Revollo, 2012).

Los resultados de la investigación de Osorio (2008), en su artículo "Forced Displacement among Rural Women in Colombia” publicado por $S A G E$, apuntan algunas de las características de esta migración forzada en la que cada vez más mujeres son las protagonistas. La autora sostiene que las mujeres son las principales sobrevivientes del conflicto armado colombiano, y que inclusive en las situaciones complicadas ellas asumieron la reconstrucción material y simbólica de la familia. Ellas también son marcadas por la pérdida y por la rabia de tener sus cuerpos transformados en territorio militar, pues son víctimas de abusos y violaciones. Asimismo, estas mujeres van reconstruyendo referencias de territorios y de identidades en 
cuanto desarrollan múltiples formas de resistencia en medio del empobrecimiento y de la exclusión social. Ellas asumen lideranzas en espacios domésticos y públicos recuperando su autoestima y reconocimiento social, aunque viviendo en doloridas situaciones llenas de inseguridad.

La mujer víctima está más próxima a la actividad y a la acción, a diferencia de lo que tradicionalmente la sociedad patriarcal/colonial caracteriza como mujer víctima. Con la mirada crítica del feminismo decolonial, el cual enfatiza la conspiración entre patriarcado y colonialismo (Lugones, 2008), busca por medio de abordajes pluridisciplinares problematizar las cuestiones de la representación y marginalización, relacionándolo al contexto histórico y geográfico. Por lo anterior, se debe reconocer a las mujeres víctimas como actoras políticas en el contexto colombiano. Ellas están en el proceso de reconocimiento, por medio de su militancia política, la cual le da sentido a sus vidas y a la vez las vuelve a colocar en riesgo inminente de victimización, ya que el surgimiento de una nueva actora en la escena política colombiana no es del agrado para el hegemónico escenario político del país.

Destaco que el levantamiento de la categoría de víctima, desde la perspectiva de las mujeres que dieron su testimonio, surge desde la construcción colectiva. Ellas van tejiendo esta categoría desde sus procesos de militancia política. Es en el encuentro, en la unión y en la lucha colectiva por sus derechos, (y más allá) por la construcción de un país incluyente, donde todas/os las/os actoras/es sociales y políticas/os participen. Considero pertinente enfatizar que es en plural que esta categoría es enunciada por las mujeres víctima(s), recordando que es en lo colectivo donde esta torna movimiento (Revollo, 2015).

En este segundo momento de la sección de los resultados, es importante recordar que las mujeres víctimas que testimoniaron en la investigación fueron victimizadas por los paramilitares entre los años 2004-2014 en diferentes localidades del país y destacar que sus procesos de militancia política en el movimiento nacional de víctimas están directamente relacionados a la construcción de las normativas de atención a la mujer desplazada generada por la Sentencia T-025/04 (Corte Constitucional, 2004). En la que se concluyó que la política estatal sobre el desplazamiento constituía un "estado de cosas inconstitucional", respondiendo la Corte Constitucional a las tutelas presentadas por la población en situación de desplazamiento y que no encontraban eco en las instituciones que operan dando cuerpo al Sistema Nacional de Atención Integral a la Población Desplazada (SNAIPD). De esta sentencia se derivan varios autos: el Auto 092 y el Auto 237 de 2008, y el Auto 009 de 2015.

Y hay otra audiencia, la audiencia de mujeres también pusimos delitos y comenzar a hablar a nivel nacional de empalamientos que sí estaban ocurriendo en Tumaco y a sus alrededores, desapariciones de chicas y esas cosas, también antes el magistrado Manuel Cepeda, y allí es donde 
se desprenden la cantidad de "autos" que se caen, en el 2008 que cae el auto de niños y niñas, sale el "auto" de comunidades negras, sale el "auto" de mujeres del 092, sale el auto de comunidades indígenas, también hicieron su audiencia que es el del 004 y así sucesivamente, una concesionaria para las víctimas que no somos ni abogadas, ni psicólogas, ni trabajadoras sociales, tanta normatividad que las mujeres decían la Corte nos entregó un carro, es que la Corte nos entregó una buseta, entonces el aprender que el "auto" es una herramienta para exigir los derechos de cierta comunidad, fue también un trabajo de nosotras. (Aline ${ }^{11}$, comunicación personal, 28 de febrero de 2014)

El testimonio de Aline evidencia cómo las normativas y sus procesos burocráticos se imponen en el cotidiano de las mujeres. Se puede pensar que este tipo de normativas representa al sistema burocrático urbano blanco masculino eurocentrado y capitalista que las acoge en las grandes ciudades.

En el testimonio que veremos a continuación, Aline evidencia la ambivalencia del sistema normativo burocrático del Estado, que atiende y cuida a las víctimas mujeres del desplazamiento forzado, pero a la vez las victimiza y amenaza, permitiéndonos entender la problemática de los múltiples rostros de la institucionalidad del Estado colombiano en lo referente al abordaje de las víctimas mujeres:

¿Qué estamos haciendo las mujeres mal, para que esto ocurra?, allí comenzamos a hacer una reflexión, algo de lo que dicen la gran mayoría de panfletos ${ }^{12} \ldots$ porque nos están amenazando porque estamos en contra, además las políticas no las escribimos las mujeres víctimas, las escribieron otros, amenacen a otros, a nosotras nos entregan un papel, nos formamos en estos y es esto que estamos diciendo no nos lo estamos inventando y no estamos diciendo nada de lo que ellos no hayan dicho ${ }^{13}$. A las mujeres lideresas defensoras de derechos humanos en donde el mensaje era el mismo, esto nos dio mucho susto, a mí ya me habían golpeado. Y en Casa de la Mujer en diciembre del 2009 que fue muy caótico, se decide pedir medidas cautelares ante la Comisión Interamericana de Derechos Humanos para 15 mujeres líderes. Y la Corte acepta y decide dar medidas cautelares. Medidas cautelares que, yo llegué llorando más de una vez a la Defensoría del Pueblo a decirle a la doctora que era la delegada de mujer, niñez y juventud, decirle quíteme las medidas cautelares porque se convirtieron en un sida, porque nuestros compañeros líderes de la población víctima de muchas

\footnotetext{
${ }^{11}$ Seudónimo.

${ }^{12}$ Panfletos con mensajes de amenazas.

${ }^{13}$ Se refiere a la legislación del Auto 092/08 y la capacitación para hacer uso de estos.
} 
organizaciones, decían algo como, ustedes ya están bien, ustedes ya tienen medidas cautelares, pero yo hasta ahora no entiendo en qué consisten las medidas cautelares. (Aline, comunicación personal, 28 de febrero de 2014).

La crítica del testimonio de Aline hace énfasis en que los protocolos de seguridad para trabajar con las mujeres víctimas son diseñados desde una lógica patriarcal y clasista de protección y cuidado. En este punto, para la época, la transversalidad de la atención con enfoque de género, a esta población, no se había hecho con un análisis interseccional. En esta línea, Aline continúa:

\begin{abstract}
Protección para mujeres es: dos escoltas, es decir dos hombres armados, una camioneta blindada, equipos de celular y el chaleco, entonces yo les decía "a mí los hombres que me agredieron eran dos hombres armados, ¿y ustedes me van a poner dos hombres armados para que me cuiden?”. Ahora yo vivo en la ciudad periférica de Bogotá, vivo en Ciudad Bolívar, yo qué voy a hacer con una camioneta blindada... En Ciudad Bolívar hay de todos los bandos. Yo no quise aceptar su esquema de protección, lo que me dijeron es, tome un equipo de celular que a veces se le va la señal, tome un equipo de Avantel que todo el mundo conoce o sabe que quien tiene Avantel o son policías o son militares o algo pasa... el esquema de protección no pueden ser hombres armados y menos con nosotras porque nosotras somos mujeres, somos mamás y vivimos en zona periférica además a nosotras nunca nos han atendido el tema psicosocial.Y me piden cuál es la protección para las mujeres, pero que vayan mujeres, no pueden ir hombres a decidir por la protección de las mujeres y que los estudios de riesgo que se hacen en Colombia para las mujeres lo hagan mujeres expertas y no solo que sean expertas sino que sean sensibles con el tema. (Aline, comunicación personal, 28 de febrero de 2014)
\end{abstract}

En el contexto del testimonio de Aline se observa cómo el enfoque transversal diferenciado de género, que ha sido diseñado por la institucionalidad del Estado colombiano para el trabajo con las víctimas mujeres, también las ha victimizado en el momento de exigir su cumplimiento. Las mujeres víctimas han sido amenazadas y agredidas psicológica y/o físicamente, y por estas amenazas y agresiones se les conceden las medidas cautelares, las cuales son diseñadas en un enfoque de protección patriarcal, racista y clasista, demostrando los límites y la no transversalidad del sistema de atención a las víctimas con enfoque de género.

En esta tercera parte de los resultados pretendo analizar cómo la mujer en el conflicto armado ha sido victimizada en todos sus roles de mujer; siendo madre, siendo compañera y siendo militante de los procesos políticos del movimiento de víctimas. 


\begin{abstract}
Allí comienzan los problemas familiares internos. El papá de mis hijos ya decía pues, él me golpea de una manera brutal y mientras él me está golpeando me dice: "Usted antes de que la mate otro la mato yo y yo se lo he dicho que se salga de esto y no se quiere salir". (Aline, comunicación personal, 28 de febrero de 2014)
\end{abstract}

Pero cuando se están haciendo los refugios infantiles mi hijo mayor sufrió un atentado, lo hirieron gravemente, le dan un impacto de bala en la barriga que se salvó de puro milagro. (Edelmira, comunicación personal, 18 de febrero de 2014)

En la intimidad de sus testimonios se revelan detalles que hablan acerca de cómo la victimización de la mujer en situación de desplazamiento sucede entre las tramas de la cotidianidad y subjetividades, inseridas en una sociedad patriarcal que violenta, invisibiliza y subestima el carácter de género de estos elementos y hechos, como lo expresan los testimonios de una madre y una compañera agredidas.

Continuando con este tercer punto del análisis de los resultados, se evidencia cómo las mujeres víctimas del desplazamiento llegan en extrema necesidad a las grandes ciudades, en muchos casos responsables de la manutención de la familia. En contextos urbanos, donde no saben cómo opera el sistema burocrático para la población víctima (al que se van a ver enfrentadas) y la demora de la llegada de esta ayuda, son obligadas a entrar en la lógica del "intercambio de favores" con lo que denominó los "hombres urbanos"14.

\begin{abstract}
(...) y claro que te marca el ser mujer y hay otra cosa que pasa especialmente con la gente joven, en muchas tuvieron que ejercer la prostitución y si no es una prostitución digamos declarada sí es un poco es soterrada, tapada porque al lado del favor de que yo te ayudo ese ayudo es entre comillas, nadie te da nada gratis y una cosa de la gente acabar cediendo y termina haciendo muchas situaciones con su cuerpo, acá sí nos hemos dado cuenta de que pasa mucho de que las mujeres terminan teniendo relaciones por eso, con la tal ayuda y se someten a la prostitución y eso pasa mucho con las jóvenes para tener un apoyo para tener algo de dinero, y es que es muy fácil de hacer porque si yo tengo el poder, si yo no tengo nada, pues es mucho más fácil de esa forma, tengo el que me ayuda, el que me colabora, pero si uno tiene más o menos unos niveles de dignidad es lo que no te permite llegar a eso. (Inés, comunicación personal, 15 de febrero de 2014)
\end{abstract}

\footnotetext{
${ }^{14}$ La dominación "hombre urbano" se refiere a los sujetos de género masculino que se aprovechan de la vulnerabilidad de las mujeres víctimas que están llegando a la ciudad, en la lógica de “intercambio de favores” entre los compañeros de las organizaciones y otros hombres que se van encontrando en el contexto de la vida urbana.
} 
Como lo podemos observar en los testimonios anteriores, los espacios de las mujeres víctimas del desplazamiento se desarrollan entre tramas intersubjetivas de las experiencias de su cotidiano (en contextos domésticos y públicos), regidas por la lógica del sistema patriarcal hegemónico en la sociedad colombiana. En los testimonios es evidente cómo las mujeres víctimas han sido oprimidas y violentadas durante toda su trayectoria, inicialmente por sus maridos y padres, por los actores armados, por los compañeros de lucha, por las organizaciones que han conformado, por la institucionalidad del Estado y por ciudadanos del común que buscan aprovecharse sexualmente de ellas, de cara a su vulnerabilidad.

Pero, a su vez, se observa cómo el desarrollar sus actividades del proceso de militancia en el movimiento de base de las mujeres víctimas, les ha permitido ser conscientes de las opresiones de la sociedad patriarcal que las victimiza. Ellas han emprendido la lucha para liberarse de esta lógica de dominación, por medio de la problematización de sus cotidianos, la creación de organizaciones de mujeres, grupos de mujeres dentro de la organizaciones existentes, peticiones concretas de atención ante el Estado colombiano, desarrollo de actos culturales y políticos que discuten el papel de las mujeres en el conflicto y la ayuda informal entre las redes de amigas, vecinas, familiares, para articularse en los procesos de base del movimiento de víctimas.

\section{A manera de conclusión}

Es fundamental destacar la centralidad de los testimonios para realizar la deconstrucción de la categoría de mujeres víctimas desde una perspectiva del feminismo decolonial y poscolonial. Este camino teórico-metodológico implicó destacar las experiencias relacionadas a las dinámicas de victimización de las mujeres víctimas del desplazamiento, vivenciadas por su misma condición de víctimas. Fue fundamental analizar las revictimizaciones, desde la perspectiva género, en el cotidiano de sus procesos de militancia política, para problematizar la enunciación de la categoría mujeres víctimas "activas y felices"15.

Los testimonios evidencian que la categoría de mujeres víctimas está cargada de innumerables especificidades, y es necesario detenernos a comprender lo que esconde el cotidiano de estas mujeres, después de su desplazamiento, cuestionando la idea de que las mujeres víctimas al llegar a las ciudades y estar amparadas por las normativas del Estado están protegidas. En contraposición se destaca el lugar diferenciado de las mujeres víctimas, como incansables gestoras de procesos propios de militancia política, los cuales reestructuran sus cotidianos y construyen un país con justicia social, que garantice el retorno a sus regiones.

\footnotetext{
${ }^{15}$ La publicación del informe ¡BastaYa! del Centro Nacional de Memoria Histórica-CNMH (2013), enfatiza que la principal característica de las víctimas colombianas es la capacidad activa de reestructurar sus vidas después del hecho victimizante, por medio de la creación de variados y creativos procesos de reconstrucción y lucha.
} 
Esta deconstrucción es un aporte de la psicosociología de comunidades, que permite entender la intersubjetividad de las sujetas en relación a su cotidianidad, como una práctica de resistencia-reexistencia, destacando la necesidad de reflexionar sobre de las diferentes maneras de estigmatización de la categoría de mujeres víctimas, para visualizar horizontes que discutan el lugar de la mujer víctima en la estructuración de una país en fase de posconflicto.

\section{Referencias}

Anzaldúa, G. (2005). La conciencia de la mestiza / Rumo a uma nova consciencia. Revista Estudos Feministas, 13 (3), 04-19.

Bahri, D. (2004). Feminism in/and Postcolonialism. En N. Lazarus. (Comp.), The Cambridge Companion to Postcolonial Literary Studies (pp. 199-220). Cambridge: Cambridge University Press.

Centro Nacional de Memoria Histórica -CNMH-. (2013). ¡Basta Ya! Colombia: Memoria de Guerra y Dignidad. Bogotá, Colombia: Pro-Off Set.

Corte Constitucional. (2004). Sentencia T-025/04. Recuperado de http://www. corteconstitucional.gov.co/relatoria/2004/t-025-04.htm

Curiel, O. (2011). Identidades esencialistas o construcción de identidades políticas: El dilema de las feministas negras. Recuperado de http://www.ciudaddemujeres.com/articulos/IMG/ pdf/Ochy_Curiel.pdf

Das, V. (2008). Sujetos de dolor, agentes de dignidad. Bogotá, Colombia: Universidad Nacional de Colombia - Pontificia Universidad Javeriana - Instituto Pensar.

D’Ávila, M. I. y Revollo, C. (2012). Desplazamiento y “nuevas” identidades en la migración. Revista Tramas, 37, 13-31.

De Sousa Santos, B. (2008). Fim das descobertas imperiais. En B. De Sousa Santos. (Ed.), A Gramatica do Tempo: para uma nova cultura política (pp. 181-190). São Paulo, Brasil: Editora Cortez.

Fajardo, D. (2015). Estudio sobre los orígenes del conflicto social armado, razones de su persistencia y sus efectos más profundos en la sociedad colombiana. Bogotá, Colombia: Espacio Crítico.

Jimeno, M. (2008). Lenguaje, subjetividad y experiencias de violencia. En V. Das. (Ed.), Sujetos de dolor, agentes de dignidad (pp. 261-291). Bogotá, Colombia: Universidad Nacional de Colombia - Pontificia Universidad Javeriana - Instituto Pensar.

Jimeno, M. (2010). Emoções e politica: a vitima e a construção de comunidades emocionais. Revista MANA, 16 (1), 99-121. 
Deconstruyendo la categoría de mujeres víctimas del desplazamiento en Colombia

Ley 1448 de 2011 (10 de junio). Por la cual se dictan medidas de atención, asistencia y reparación integral a las víctimas del conflicto armado interno y se dictan otras disposiciones. Diario Oficial No. 48.096.

Lugones, M. (2008). Colonialidad y Género. Revista Tabula Rasa, 9, 73-101.

Miñoso, Y. (2009). Etnocentrismo y colonialidad en los feminismos Latinoamericanos: complicidades y consolidación de las hegemonías feministas en el espacio tradicional. Revista Venezolana de Estudios de la Mujer, 33, 37-54.

Mondragón, H. (2002). La organización campesina en un ambiente de terror. Recuperado de http: / / www.ilsa.org.co/biblioteca/Cuadernos_Tierra_y_Justicia/Cuadernostierrayjusticia_7/ La_organizacion_campesina_en_un_ambiente_de_terror.pdf

Osorio, F. E. (2008). Forced Displacement among Rural Women in Colombia. Latin American Perspectives SAGE, 35 (6), 29-40.

Quijano, A. (2005). La colonialidade do saber: eurocentrismo e ciências sociais, perspectivas latinoamericanas. Buenos Aires, Argentina: CLACSO.

Revollo, C. (2015). Traduciendo los testimonios de las mujeres víctimas del desplazamiento en Colombia (Tesis de Doctorado). Universidade Federal do Rio de Janeiro, Rio de Janeiro, Brasil.

Sarlo, B. (2007). Tempo passado, cultura da memoria e guinada subjetiva. São Paulo, Brasil: Editorial Companhia das Letras, Editorial UFMG.

Spivak, G. (2003). ¿Puede hablar el subalterno? Revista Colombiana de Antropología, 39, 297-364.

Walsh, C. (2009). Interculturalidad, Estado y Sociedad. Luchas (de)coloniales de nuestra época. Quito, Ecuador: Editorial Abya-Yala. 